\title{
STUDI SISTEM INJEKSI INHIBITOR KOROSI TERHADAP KANDUNGAN ORTHOFOSFAT DAN SENG SEBAGAI PARAMETER KENDALI KOROSI PADA SISTEM PENDINGIN SEKUNDER RSG-GAS
}

\author{
Edwin Rizki Safitra ${ }^{1}$, Diyah Erlina Lestari², Mita Rilyanti ${ }^{3}$ \\ ${ }^{1}$ Program Studi Teknik Kimia, Institut Teknologi Sumatera, Lampung, Indonesia \\ ${ }^{2}$ RSG-GAS BATAN Serpong, Tangerang, Indonesia \\ ${ }^{3}$ Jurusan Kimia, Universitas Lampung, Lampung, Indonesia
}

\begin{abstract}
Reaktor Serba Guna G.A Siwabessy (RSG-GAS) was built since 1983. RSG-GAS is a type of research reactor equipped with heat carrier and cooling system which serves to remove heat arising from fission reactions. In the heat carrier medium, the reactor equipped with a secondary cooling system using water originating from PAM Puspiptek. Water used in secondary cooling systems can cause some major problems of crust, corrosion, and moss or microorganisms. In this research, the phosphorus (orthophosphate), zinc, and conductivity and $\mathrm{pH}$ in the secondary cooling system have been measured to determine whether or not the flow rate of the injection system is used. Determination of concentration of the elements was performed using a DR / 2400 spectrophotometer portable device with ZincoVer 5 Powder Pillow reagent, cyclohexane for zinc concentration, and PhosVer 3 phophate for phosphorus concentration. From the results obtained, the overall flow rate of injector injection of $1.7 \mathrm{~L} / \mathrm{h}$ gives a good result. Significant differences occurred only in conductivity values dated July 21, 2009 both in piped water and cooling towers exceeding $950 \mu s$ / $\mathrm{cm}$. And the value of orthophosphate concentration dated August 4, 2009 that exceeds 10 ppm.
\end{abstract}

Keyword: Corrosion, Cooling System, RSG-GAS, Injection

\section{Pendahuluan}

Reaktor Serba Guna G.A Siwabessy (RSG-GAS) dibangun sejak tahun 1983. RSG-GAS mempunyai daya termal maksimum $30 \mathrm{MW}$ dan mempunyai fluks neutron rata-rata $10^{14} \mathrm{n} / \mathrm{cm}^{2}$ detik yang berasal dari reaksi fisi [1]. Reaktor ini mempunyai dua sistem pendingin yaitu sistem pendingin primer dan sekunder yang menggunakan air sebagai media pendinginnya. Air pendingin primer reaktor berfungsi untuk memindahkan panas yang timbul sebagai akibat reaksi fisi di teras reaktor. Panas yang dibebaskan di dalam teras dan sekitar reflektor diambil oleh air sistem pendingin primer dengan cara mengalirkan air pendingin lewat celah bahan bakar. Panas dipindahkan ke sistem pendingin sekunder melalui sistem penukar panas, kemudian panas tersebut dibuang ke atmosfer melalui menara pendingin beraliran udara paksa [2].

Media pembawa panas yang digunakan pada sistem pendingin primer berupa air bebas mineral. Air bebas mineral memiliki kandungan-kandungan unsur kimia yang relatif kecil [3]. Sedangkan pada sistem pendingin sekunder, media pembawa panas yang digunakan adalah air yang berasal dari PAM Puspiptek tanpa pengolahan lebih lanjut. Air yang digunakan dalam sistem pendingin sekunder dapat menimbulkan beberapa masalah pokok yaitu kerak, korosi, dan lumut atau mikroorganisme. Untuk mengatasi hal tersebut maka dilakukan pengendalian kualitas kimia air dengan menambahkan bahan inhibitor korosi secara injeksi [4]. Setelah penambahan inhibitor, dilakukan analisis secara kuantitatif menggunakan metode spektrofotometri terhadap unsur-unsur pada sistem pendingin sekunder agar tetap pada batas normalnya [5].

Pada penelitian ini dilakukan kontrol terhadap konsentrasi senyawa kimia pada air pendingin sekunder. Pengontrolan ini dilakukan secara rutin, terhadap senyawa kimia yang dapat menghambat tumbuhnya korosi antara lain orthofosfat $\left(\mathrm{PO}_{4}{ }^{3-}\right)$ dan seng $(\mathrm{Zn})$. Selain itu dilakukan pula pengukuran nilai $\mathrm{pH}$ dan konduktivitas. Pengontrolan ini dilakukan agar konnsentrasi unsur-unsur kimia dalam air pendingin berada pada batas yang tidak menyebabkan timbulnya korosi. Dengan demikian perlu dipelajari tentang pengendalian korosi pada sistem pendingin sekunder RSG-GAS, dan terutama mempelajari studi injeksi inhibitor korosi terhadap kandungan orthofosfat dan seng yang digunakan sebagai parameter kendali korosi pada sistem pendingin sekunder RSG-GAS. 


\section{Metode}

\subsection{Penentuan konsentrasi fosfor (orthofosfat)}

Larutan sampel sebanyak $10 \mathrm{~mL}$ dimasukkan ke dalam dua buah wadah sampel berupa tabung tertutup. Kedalam salah satu tabung ditambahkan 0,41 gram PhosVer 3 phosphate Powder Pillow, kemudian diaduk hingga homogen. Setelah homogen sampel didiamkan selama 2 menit. Kemudian diukur konsentrasinya terhadap larutan blanko pada tabung yang lain menggunakan alat portable spektrofotometer DR/2400.

\subsection{Penentuan konsentrasi seng dengan metode zincon}

Larutan sampel sebanyak $20 \mathrm{~mL}$ dimasukkan ke dalam labu ukur $25 \mathrm{~mL}$ dan ditambahkan 0,29 gram ZincoVer Powder Pillow, kemudian diaduk hingga homogen. Setelah homogen $10 \mathrm{~mL}$ larutan ini dimasukkan pada tabung tertutup dan digunakan sebagai blanko. Kemudian $10 \mathrm{~mL}$ berikutnya dimasukkan ke dalam tabung berikutnya yang ditambahkan $0,5 \mathrm{~mL}$ sikloheksan, diaduk selama 30 detik dan didiamkan selama 3 menit. Setelah sampel homogen kemudian diukur konsentrasinya menggunakan alat portable spektrofotometer DR/2400.

\subsection{Pengukuran pH menggunakan pH-meter}

Elektroda $\mathrm{pH}$ meter dicelupkan ke dalam larutan sampel, kemudian diangkat dan dibilas dengan air bebas mineral. Setelah elektroda benar-benar bersih kemudian dicelupkan ke dalam larutan sampel kembali dan ditentukan nilai konstan pada alat $\mathrm{pH}$ meter.

\subsection{Pengukuran pH menggunakan pH-meter}

Elektroda konduktivitas dicelupkan ke dalam larutan sampel, kemudian diangkat dan dibilas dengan air bebas mineral. Setelah elektroda benar-benar bersih kemudian dicelupkan ke dalam larutan sampel kembali dan ditentukan nilai konstan pada alat konduktivitimeter.

\section{Hasil dan Pembahasan}

Korosi merupakan salah satu masalah yang terdapat pada sistem pendingin sekunder dan keberadaannya harus dikendalikan agar tidak mengganggu aliran air serta kualitas airnya. Untuk mengendalikan adanya korosi, pada sistem pendingin sekunder dilengkapi dengan sistem injeksi inhibitor korosi yang diatur dengan laju alir 1,7 L/jam. Sebagai kontrol dari fungsi injeksi inhibitor korosi ini perlu dilakukan pengukuran kandungan orthofosfat dan seng dalam sistem pendingin sekunder. Air yang digunakan untuk mengisi cooling tower adalah air dari raw watter yang berasal dari PAM PUSPIPTEK. Oleh karena itu dilakukan juga pengukuran terhadap kandungan orthofosfat dan seng pada raw watter setiap satu minggu sekali untuk membandingkan kualitas air pada sistem pendingin sekunder. Sebagai sampel air pendingin sekunder diambil air dari pipa dan cooling tower dengan nilai $\mathrm{pH}$, konduktivitas, seng, dan orthofosfat dalam sistem pendingin sekunder sebgai berikut:

Tabel 1. Data analisis pada cooling tower

\begin{tabular}{|c|c|c|c|c|}
\hline $\begin{array}{c}\text { Waktu } \\
\text { pengambilan } \\
\text { sampel }\end{array}$ & $\mathbf{p H}$ & $\begin{array}{c}\text { Konduktivitas } \\
(\boldsymbol{\mu s} / \mathbf{c m})\end{array}$ & $\begin{array}{c}\text { Kadar orthofosfat } \\
(\mathbf{p p m})\end{array}$ & Kadar seng (ppm) \\
\hline $14-07-09$ & 8,3 & 926 & 8,05 & 0,63 \\
\hline $21-07-09$ & 8,4 & 966 & 5,05 & 0,54 \\
\hline $27-07-09$ & 8,47 & 855 & 5,45 & 0,47 \\
\hline $28-07-09$ & 8,15 & 897 & 7,25 & 0,46 \\
\hline $29-07-09$ & 8,38 & 911 & 7,4 & 0,43 \\
\hline $30-07-09$ & 8,26 & 920 & 7,25 & 0,46 \\
\hline $31-07-09$ & 8,17 & 889 & 5,25 & 0,46 \\
\hline $31-07-09$ & 8,48 & 899 & 8,4 & 0,58 \\
\hline
\end{tabular}




\begin{tabular}{|c|c|c|c|c|}
\hline $3-08-09$ & 8,47 & 884 & 9,25 & 0,62 \\
\hline $4-08-09$ & 8,06 & 912 & 10,15 & 0,53 \\
\hline $5-08-09$ & 8,04 & 922 & 9,9 & 0,55 \\
\hline $6-08-09$ & 8,18 & 921 & 7,45 & 0,47 \\
\hline $7-08-09$ & 8,19 & 926 & 7,15 & 0,42 \\
\hline
\end{tabular}

Dari Tabel 1 dan 2 terlihat secara umum bahwa dengan beroperasinya sistem pendingin sekunder berangsur-angsur kandungan orthofosfat dan seng dalam air pendingin sekunder akan meningkat dan akan menurun setelah blow down (pembuangan air pada boiler). Hal ini disebabkan karena adanya blow down, yang terjadi jika kontrol level batas bawah pada cooling tower telah tercapai. Selanjutnya akan menyebabkan berkurangnya air pada cooling tower dan secara otomatis terjadi penambahan air (make up water) dari air pemasok (raw water). Tetapi apabila dilihat secara seksama, bahwa tidak selalu penurunan kandungan orthofosfat dan seng dalam air pendingin sekunder disebabkan karena adanya blow down. Seperti terlihat pada data tanggal 21 Juli '09 walaupun blow down belum terjadi, tetapi kandungan orthofosfat dan seng dalam air pendingin sekunder menurun. Hal ini disebabkan karena selama sistem pendingin beropeasi akan terjadi percikan dan penguapan yang mengakibatkan hilangnya atau berkurangnya air pada cooling tower.

Tabel 2. Data analisis pada air pipa

\begin{tabular}{|c|c|c|c|c|}
\hline $\begin{array}{c}\text { Waktu } \\
\text { pengambilan } \\
\text { sampel }\end{array}$ & $\mathbf{p H}$ & $\begin{array}{c}\text { Konduktivitas } \\
(\boldsymbol{\mu s} / \mathbf{c m})\end{array}$ & $\begin{array}{c}\text { Kadar orthofosfat } \\
(\mathbf{p p m})\end{array}$ & Kadar seng (ppm) \\
\hline $14-07-09$ & 8,3 & 926 & 7,55 & 0,79 \\
\hline $21-07-09$ & 8,4 & 966 & 5,2 & 0,55 \\
\hline $27-07-09$ & 8,45 & 855 & 5,5 & 0,39 \\
\hline $28-07-09$ & 8,4 & 897 & 7,3 & 0,51 \\
\hline $29-08-09$ & 8,36 & 911 & 5,85 & 0,53 \\
\hline $30-07-09$ & 8,27 & 920 & 7,5 & 0,45 \\
\hline $31-07-09$ & 8,16 & 889 & 5,45 & 0,53 \\
\hline $31-07-09$ & 8,48 & 899 & 8,1 & 0,60 \\
\hline $3-08-09$ & 8,68 & 884 & 10 & 0,61 \\
\hline $4-08-09$ & 8,12 & 912 & 10,3 & 0,54 \\
\hline $5-08-09$ & 8,18 & 922 & 9,6 & 0,56 \\
\hline $6-08-09$ & 8,1 & 921 & 7,1 & 0,51 \\
\hline $7-08-09$ & 8,18 & 926 & 6,9 & 0,5 \\
\hline
\end{tabular}

Dengan melihat data deskripsi sistem pendingin sekunder pada Tabel 3, dapat dihitung volume hilangnya air pada cooling tower yaitu $37 \mathrm{~m}^{3} / \mathrm{jam}$, laju air make up yaitu $43 \mathrm{~m}^{3} / \mathrm{jam}$, dan volume air yang ditambahkan pada saat terjadi untuk make up yaitu $51,84 \mathrm{~m}^{3}$. Dari data ini diketahui bahwa waktu yang diperlukan untuk make up yaitu 1,20 jam dan setiap 1,4 jam baru terjadi make up. Oleh karena itu dengan adanya pengoperasian injeksi inhibitor korosi secara kontinyu akan menyebabkan kenaikan atau kepekatan kandungan orthofosfat apabila penambahan air (make up water) belum terjadi. Tetapi sebaliknya akan mengalami penurunan kandungan orthofosfat apabila penambahan air (make up water) terjadi secara bersamaan dengan blow down seperti terlihat pada data tanggal 31 Juli '09. 
Tabel 3. Data Deskripsi Sistem Pendingin Skunder

\begin{tabular}{|l|l|}
\hline \multicolumn{1}{|c|}{ Sistem pendingin sekunder } & \multicolumn{1}{c|}{ Ukuran } \\
\hline Luas cooling tower & $370,3 \mathrm{~m}^{2}\left(23^{*} 16,1\right)$ \\
\hline Laju penurunan air karana evaporasi dan percikan & $0,1 \mathrm{~m} / \mathrm{jam}$ \\
\hline Laju injeksi korosi & $1,7 \mathrm{~L} / \mathrm{jam}$ \\
\hline Batas make up & $0,14 \mathrm{~m}(4.18-4.32) \mathrm{m}$ \\
\hline Massa jenis inhibitor korosi & $1,226 \mathrm{gr} / \mathrm{mL}$ \\
\hline Laju sistem make up & $80 \mathrm{~m}$ /jam \\
\hline
\end{tabular}

Penurunan konsentrasi orthofosfat pada tanggal 4-7 Agustus '09 disebabkan karenan sistem pendingin sekunder telah shut down dan sistem injeksi inhibitor korosi secara kontinyu tidak beroperasi yang membuat fosfat aktif dalam bentuk orthofosfat membentuk lapisan endapan tipis yang secara efektif untuk melindungi permukaan logam yang lemah dari serangan zat-zat agresif.

\section{Kesimpulan}

Dari hasil yang telah dilakukan dapat disimpulkan bahwa pengoperasian sistem injeksi inhibitor korosi secara kontinyu belum sepenuhnya dapat mempertahankan konsentrasi inhibitor korosi sesuai yang diharapkan. Pada sistem pendingin sekunder orthofosfat lebih berperan sebagai pelindung korosi daripada seng, hal ini dikarenakan orthofosfat akan membentuk lapisan endapan tipis yang secara efektif untuk melindungi permukaan logam yang lemah dari serangan zat-zat agresif.

\section{Penghargaan}

Edwin Rizki Safitra (Penulis) mengucapkan terima kasih kepada tim Reaktor Serba Guna G.A Siwabessy (RSG-GAS) BATAN dikarenakan hasil ini merupakan penelitian saat penulis melaksanakan Kerja Praktek. Penulis juga mengucapkan terima kasih kepada Ibu Diyah Erlina Lestari dan Ibu Mita Rilyanti sebagai pembimbing penulis selama mengerjakan penelitian ini.

\section{Daftar Pustaka}

[1] Lestari, Diyah,. 2008. "Kimia Air, Pelatihan Operator dan Supervisor Reaktor Riset". Pusat Pendidikan dan Pelatihan BATAN. Serpong.

[2] Djunaidi., Setyo Budi Utomo. 2007, "Pemakaian Inhibitor untuk Pengendalian Korosi pada Sistem Pendingin Sekunder RSG-GAS", Vol.4, No.2, Buletin Pengelolaan Reaktor Nuklir.

[3] Lestari, Diyah., 2004, "Kimia Air Reaktor Riset G.A.Siwabessy" Makalah Penelitian P2TRR dan P2TKN BATAN. Serpong.

[4] Kemmer, Frank N. 1979, "The NALCO Water Handbook" McGrow-Hill Book Company. New York.

[5] Nunn, Robert G. 1997, "Water Treatment Essentials for Boiler Plant Operation McGraw-Hill. New York. 